\title{
Hospitalization outcomes in patients with schizophrenia after switching to lurasidone or quetiapine: a US claims database analysis
}

John W. Newcomer ${ }^{1}$, Daisy Ng-Mak ${ }^{2^{*}}$ (D, Krithika Rajagopalan² and Antony Loebel ${ }^{3}$

\begin{abstract}
Background: This study compared hospital admission rates among adult patients with schizophrenia who switched to antipsychotic monotherapy with lurasidone or quetiapine.

Methods: This retrospective cohort study used U.S.-based Truven Health MarketScan ${ }^{\oplus}$ Medicaid Multi-State Database (April 2010 through December 2012) and MarketScan ${ }^{\oplus}$ Commercial Claims and Encounters Database (April 2010 through October 2013). Continuous enrollment for 6-months before and after medication initiation was required. Treatment episodes ended after 6-months post lurasidone or quetiapine initiation, a 60-day treatment gap, or initiation of another antipsychotic. Length of treatment episodes (i.e., treatment duration) was compared using a t-test. All-cause, mental-health, and schizophrenia-related hospitalization rates, as well as costs, were compared between lurasidone- and quetiapine-treated patients using multivariable generalized linear models that adjusted for background characteristics.
\end{abstract}

Results: Quetiapine ( $n=435)$ compared to lurasidone $(n=238)$ treatment was associated with increased all-cause ( $21 \%$ vs $13 \%, p<0.05$ ) and mental health-related hospitalizations ( $20 \%$ vs $12 \%, p<0.05$ ), but similar rates of schizophreniarelated hospitalizations (14\% vs. 10\%, $p=0.14$ ). After adjusting for baseline covariates, quetiapine had $64 \%$ higher likelihood of all-cause hospitalizations (OR [odds ratio] $=1.64,95 \%$ confidence interval $[\mathrm{Cl}]$ 1.05-2.57, $p=0.03$ ), 74\% higher likelihood of mental health-related hospitalizations $(\mathrm{OR}=1.74,95 \% \mathrm{Cl} 1.11-2.75, p=0.02)$, and a similar likelihood of schizophrenia-related hospitalization ( $\mathrm{OR}=1.35,95 \% \mathrm{Cl} 0.82-2.22, p=0.24)$. For those with hospital admissions, adjusted all-cause admission costs were higher for quetiapine when compared with lurasidone in both the Medicaid $(\$ 22,036$ vs. $\$ 15,424, p=0.17)$ and commercial populations $(\$ 23,490$ vs. $\$ 20,049, p=0.61)$. These differences were not significant. The length of treatment episodes was significantly shorter for quetiapine than lurasidone (115.4 vs 123.1 days, $p<0.05$ ).

Conclusions: In this retrospective claims database study, patients with schizophrenia who were switched to lurasidone had significantly fewer all-cause and mental health-related hospitalizations and similar rates of schizophrenia-related hospitalization compared with those switched to quetiapine. Patients switching to lurasidone had a significantly longer treatment duration rate than those switching to quetiapine. These results may reflect differences in efficacy or tolerability between lurasidone and quetiapine.

Keywords: Antipsychotic medication, Retrospective studies, Hospital, Schizophrenia

\footnotetext{
* Correspondence: Daisy.Ng-Mak@sunovion.com

${ }^{2}$ GHEOR, Sunovion Pharmaceuticals Inc., Marlborough, MA, USA

Full list of author information is available at the end of the article
} 


\section{Background}

Schizophrenia is a chronic, debilitating psychiatric disorder with a lifetime prevalence of approximately 1\% [1]. Clinically, schizophrenia is characterized by cognitive impairment, hallucinations, paranoid or bizarre delusions, and social withdrawal resulting in significant social and occupational dysfunction [2-4].

In 2013, the total cost of schizophrenia in the U.S. was estimated at $\$ 155.7$ billion [5]. Approximately $\$ 37.7$ billion of the total cost derives from direct healthcare costs, with $\$ 15$. 2 billion of those costs resulting from inpatient care [5-7]. Hospitalizations are a major component of healthcare costs among patients with schizophrenia [6-8]. The risk of hospitalization increases with non-adherence to treatment, and adherence to treatment is often low $[9,10]$.

Antipsychotics, and in particular atypical antipsychotics, are recommended as the first-line treatment for schizophrenia [11]. Atypical antipsychotics have been found to be a heterogeneous class of drugs with varied efficacy and tolerability profiles [12, 13]. The literature suggests that atypical antipsychotics may contribute to varying degrees to cardiometabolic risk in patients with schizophrenia [14, 15], including aggravation of preexisting cardiovascular disease and diabetes risk factors $[16,17]$.

Optimizing antipsychotic treatment for the longterm management of patients with schizophrenia frequently involves the need to switch medication. Over time, patients may be treated with a series of different antipsychotics, with limited evidence-based guidance available to inform clinicians' choice of the next antipsychotic. In the Clinical Antipsychotic Trials of Intervention Effectiveness (CATIE), which consisted of three 18-month sequential clinical trials in schizophrenia, $74 \%$ of participants discontinued their first antipsychotic during the initial phase [18], $69 \%$ or $74 \%$ discontinued their second antipsychotic in the next phase $[19,20]$, and $39 \%$ discontinued their third antipsychotic in the final phase [21]. Quetiapine and lurasidone are atypical antipsychotics approved by the U.S. Food and Drug Administration (FDA) for the treatment of patients with schizophrenia in 1997 and 2010, respectively [22, 23]. When comparing patients with schizophrenia treated with lurasidone or quetiapine XR, a previously-reported double-blind, clinical trial showed that those treated for 12-months with lurasidone had a statistically significantly reduced risk of hospitalization [24]. The extent to which these findings apply to patients with schizophrenia in realworld treatment settings remains unknown. The primary objective of this study was to confirm and extend these findings by assessment of hospitalization rates among patients with schizophrenia who switched to antipsychotic monotherapy with lurasidone or quetiapine from other atypical antipsychotics in realworld settings. The secondary objectives of this study were to describe treatment duration and total inpatient admission costs for Medicaid and commercial payers.

\section{Methods}

\section{Study design and database}

This retrospective cohort study used U.S. administrative medical and pharmacy claims data from the Truven Health MarketScan ${ }^{\circledR}$ Medicaid Multi-State Database for the period April 1, 2010 through December 31, 2012 and the MarketScan ${ }^{\oplus}$ Commercial Claims and Encounters Database for the period April 1, 2010 through October 31, 2013. Data access was provided based on a licensing agreement between Truven Health and Sunovion Pharmaceuticals Inc. Both databases contain healthcare claims data for patients with Medicaid or employer-sponsored primary insurance. The Medicaid Multi-State Database includes the claims of millions of patients insured by Medicaid from multiple states. Medicaid coverage differs from state to state, and generally includes healthcare coverage for low-income families and individuals as well as individuals with disabilities [25]. The Commercial Claims and Encounters Database includes the claims of patients and their families who are insured through their employers.

All study data were fully compliant with the Health Insurance Portability and Accountability Act (HIPAA) of 1996, and therefore the study did not require approval or waiver from an institutional review board [26]. Please see Fig. 1 for a study design diagram.

\section{Patient selection criteria}

Medicaid and commercial patients were selected separately. All patients included in this study were adults (at least 18 years of age) and diagnosed with schizophrenia (defined by one inpatient or outpatient claim with an International Classification of Diseases, Ninth Revision, Clinical Modification [ICD-9-CM] diagnosis code of 295.xx, where $x$ could be any digit). The 1-year study period was defined as a pre-index period of 6-months prior to the index date, the index date, and a follow-up period of 6-months after the index date. The index date was defined as the date of the first prescription fill of either lurasidone or quetiapine. All patients were required to be continuously enrolled with medical and prescription drug benefits throughout the study period. Patients included in the study were required to switch from another oral atypical antipsychotic (aripiprazole, asenapine, clozapine, iloperidone, olanzapine, paliperidone, risperidone, or ziprasidone) during the pre-index period to antipsychotic monotherapy with either quetiapine or lurasidone. 


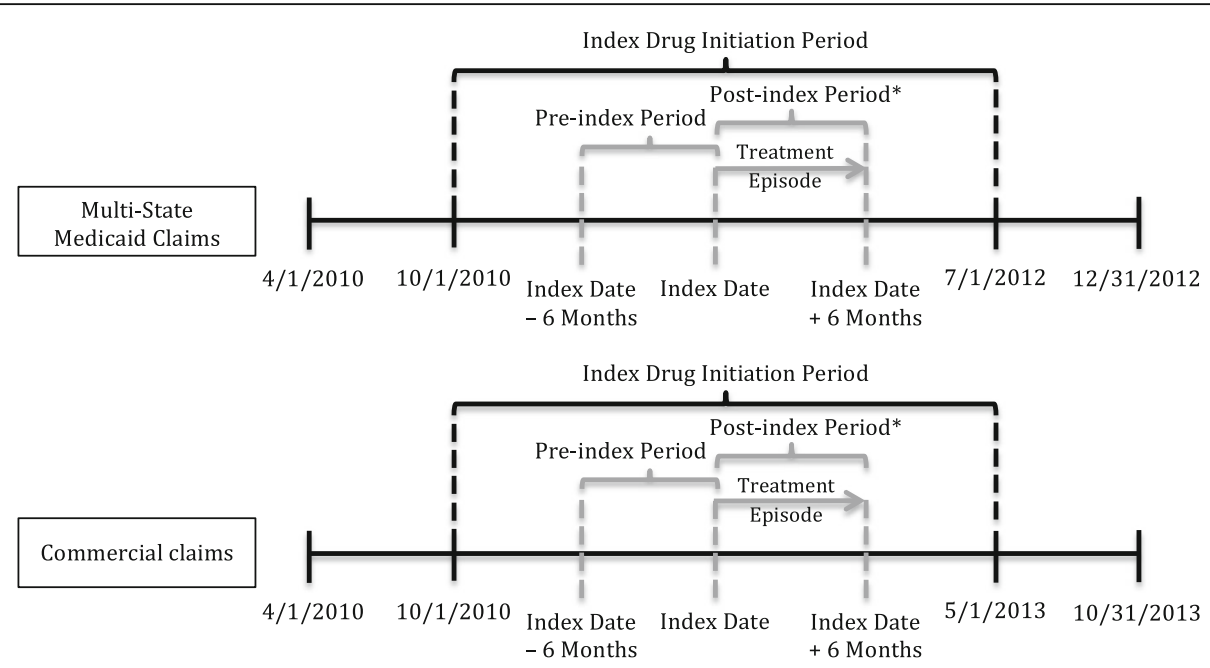

Fig. 1 Study design and timeline diagram. The pre-index variables were evaluated from claims during the 6-month pre-index period. The index date was defined as the date of first prescription fill of lurasidone or quetiapine. The outcome variables were evaluated from claims in the 6-month follow-up (postindex) period. Treatment episodes began at, or after, the index date, and could have ended prior to the end of the 6-month follow-up period if the either of the following occurred: treatment discontinuation or a switch to another antipsychotic

\section{Treatment episodes}

Treatment episodes were defined by at least two lurasidone or quetiapine prescriptions without overlapping prescriptions for other antipsychotics (atypical, typical, or depot) during the follow-up period. Treatment episodes began on the index date and continued until one of the following: treatment discontinuation (gap of 60 or more days with no index medication), switch to another antipsychotic (initiation of antipsychotic other than the index medication with a gap or overlap of 30 or less days between treatments), or the end of the study's 6-month follow-up period. Each patient could have multiple treatment episodes. Patients were still included in the analysis if they had switched to a different therapy after one treatment episode ended, and then re-initiated a second treatment episode with either quetiapine or lurasidone monotherapy. The proportion of patients with more than one treatment episode was calculated. Overall treatment duration was defined as the number of days from the start to the end of the treatment episode during the 6-month follow up period.

\section{Pre-index covariates}

Patient pre-index variables were extracted from claims data during the 6-months prior to the index date or on the index date. Psychiatric and cardiometabolic comorbidities were defined based on ICD-9-CM codes (see Additional file 1 for specific codes). Pre-index medications were based on any use of antidepressant, anxiety, hypnotic, mood stabilizer, and stimulant medications as identified using Redbook therapeutic classes. Pre-index atypical antipsychotics included: aripiprazole, asenapine, clozapine, iloperidone, olanzapine, paliperidone, risperidone, and ziprasidone.

\section{Study outcomes}

The main outcome variables were rates of all-cause, mental-health, and schizophrenia-related hospitalizations. Hospitalizations were determined based on the facility claim information. If a patient had facility claims separated by less than one day the claims were considered to be from a single hospitalization. All-cause hospitalization was defined as any hospitalization with any diagnosis during the follow-up period. Mental health-related hospitalization was defined as those with an ICD-9-CM code from 290.xx - 314.xx in the primary or secondary diagnosis position. Schizophrenia-related hospitalization was defined as those with an ICD-9-CM code of 295.xx in any position. Hospitalization rates were examined separately in the Medicaid and commercial payer populations. The proportion of treatment episodes with at least one hospitalization and the length of stay for the first hospitalization were also investigated.

This was a cost of illness study. Due to large differences in payment structures and patient populations, healthcare costs were analyzed separately for the Medicaid and commercial payer populations. Healthcare costs were based on the paid amounts of adjudicated claims, including insurer and health plan payments, as well as patient cost-sharing in the form of copayment, deductible, and coinsurance. Because the most recent year in the Medicaid database was 2012, costs were adjusted for inflation and standardized to 2012 US dollars using the Consumer Price Index from the US Bureau of Labor Statistics [27]. 


\section{Statistical methods}

Given the high frequency of treatment switching in this population, treatment was studied at the episode level, rather than the patient level. The treatment episode methodology was employed in this analysis to facilitate attribution of hospitalizations to a specific medication [28]. Pre-index characteristics were summarized using means and standard deviations for continuous measures and counts and percentages for categorical measures. Differences between cohorts during the pre-index period were assessed using chisquare tests for categorical variables and t-tests or ANOVA for continuous measures.

For the outcome variables, multivariable generalized linear models were used to statistically adjust for pre-index characteristics while accounting for the within-patient correlation among patients with multiple episodes by using random effect. The models were adjusted for age, gender, payer type, inpatient admissions during the pre-index period, anxiety disorder, depression disorder, alcohol/substance abuse disorder, and anti-anxiety medication use. For probability of resource use, a model with a binomial distribution and logit link was used to compare differences in the probability of hospitalization while controlling for pre-index characteristics. For patients with at least one hospitalization, a model with a gamma distribution [29] with log link was used to compare differences in hospitalization costs while controlling for pre-index characteristics. $P$ values $<.05$ were considered, a priori, to be statistically significant. All analyses were completed with SAS version 9.3 (SAS Institute, Cary, NC).

\section{Results}

\section{Patient characteristics}

The database contained 68,194 patients enrolled in Medicaid and 264,039 patients enrolled in commercial insurance during the study period with a first-time prescription for either lurasidone or quetiapine (please see patient flow diagrams, Fig. 2). The number of adults with continuous insurance enrollment with medical and drug benefits throughout the 1-year study period in the database was $139,753(19,950$ Medicaid and 119,803 commercial). Only $3653 \mathrm{Me}-$ dicaid patients and 3120 commercial patients had a schizophrenia diagnosis (ICD-9-CM diagnosis code 295.xx) during the pre-index period. Of the patients with schizophrenia diagnoses, 649 Medicaid and 692 commercial patients switched from oral aripiprazole, asenapine, clozapine, iloperidone, olanzapine, paliperidone, risperidone, or ziprasidone treatment to lurasidone or quetiapine. Only patients treated with lurasidone or quetiapine as antipsychotic monotherapy were included (337 Medicaid and 336 commercial). Contained in the final sample were 122 Medicaid and 116 commercial patients treated with lurasidone monotherapy, and 215 Medicaid and 220 commercial patients treated with quetiapine monotherapy.

Table 1 provides the patient characteristics for the combined population, as well as for separated Medicaid and commercial payer populations during the pre-index period. In the combined population, lurasidone and quetiapine cohorts were largely similar, with a few notable exceptions. The lurasidone cohort had more females $(61 \%$ vs. $52 \%, p<0.05)$ than the quetiapine cohort. The prevalence of depression ( $42 \%$ vs. $52 \%, \mathrm{p}<0.05)$, anxiety $(28 \%$ vs. $39 \%, \mathrm{p}<0.05)$, and alcohol/substance abuse disorder $(22 \%$ vs. $37 \%, \mathrm{p}<0.05)$ was significantly higher for the quetiapine patients than lurasidone patients. While lurasidone patients were more likely to have switched from asenapine or olanzapine, quetiapine patients were more likely to have switched from risperidone $(p<0.05)$. Quetiapine patients also had significantly higher inpatient admission rates during the pre-index period. Overall, multiple monotherapy episodes were uncommon for patients in either the lurasidone $(2 \%)$ or quetiapine $(3 \%)$ cohorts. The average daily dose of quetiapine increased significantly during the treatment episodes (mean \pm SD first prescription vs. last prescription: $265 \pm 256$ vs. $306 \pm 315 \mathrm{mg} p<0.05$ ), while the average daily dose of lurasidone was largely unchanged (mean \pm SD first prescription vs. last prescription: $68 \pm$ 105 vs. $74 \pm 105 \mathrm{mg}, p=0.53)$.

\section{Hospitalizations during the 6 months follow up period}

Prior to adjusting for pre-index covariates, lurasidonetreated patients experienced fewer treatment episodes resulting in any hospitalization ( $13 \%$ vs. $21 \%, \mathrm{p}<0.05)$, mental health-related hospitalization (12\% vs. $20 \%, \mathrm{p}<0$. 05 ), but not schizophrenia-related (10\% vs. $14 \%, p=0$. 14) hospitalization compared to quetiapine-treated patients. Results from the multivariable generalized linear model that adjusted for pre-index covariates demonstrated that compared to the lurasidone cohort, quetiapine-treated patients had 64\% higher odds of all-cause hospitalization $(\mathrm{OR}=1.64,95 \%$ CI [1.05, 2 . 57] $p=0.03)$ and $74 \%$ higher odds of mental healthrelated hospitalization $(\mathrm{OR}=1.74,95 \% \mathrm{CI}[1.11,2.75]$, $p=0.02)$, but not schizophrenia-related $(\mathrm{OR}=1.35$, 95\% CI [.82, 2.22], $p=0.24$ ) hospitalization in the post-index period (Fig. 3).

Hospitalization rates during the follow up period were higher for patients treated with quetiapine in both the Medicaid and commercial populations, although the differences did not consistently reach 


\section{a}

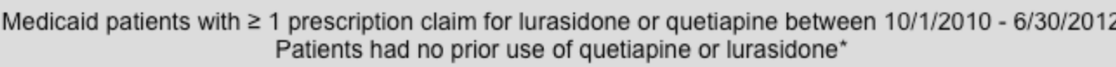

Age $\geq 18$ at index date plus 6 -month pre- and post-index continuous enrollment with medical and prescription drug benefits $(\mathrm{N}=19,950)$

Diagnosis of schizophrenia in the 6 -month pre-index period $(\mathrm{N}=3,653)$

\begin{tabular}{|c|c|}
\hline \multicolumn{2}{|c|}{ Diagnosis of schizophrenia in the 6 -month pre-index period $(\mathrm{N}=3,653)$} \\
\hline & \\
\hline \multicolumn{2}{|c|}{$\begin{array}{l}\text { Switch from oral aripiprazole, asenapine, clozapine, iloperidone, paliperidone, olanzapine, risperidone or } \\
\text { ziprasidone }(\mathrm{N}=649)\end{array}$} \\
\hline \multicolumn{2}{|l|}{$\Gamma$} \\
\hline $\begin{array}{l}\text { Lurasidone patients } \\
\qquad(\mathrm{N}=252)\end{array}$ & $\begin{array}{l}\text { Quetiapine patients } \\
\qquad(\mathrm{N}=397)\end{array}$ \\
\hline$T$ & $T$ \\
\hline $\begin{array}{l}\text { Lurasidone patients with monotherapy episodes } \\
\qquad(\mathrm{N}=122)\end{array}$ & $\begin{array}{l}\text { Quetiapine patients with monotherapy episodes } \\
\qquad(\mathrm{N}=215)\end{array}$ \\
\hline \multicolumn{2}{|c|}{$\begin{array}{l}\text { Commercially insured patients with } \geq 1 \text { prescription claim for lurasidone or quetiapine } \\
\text { between } 10 / 1 / 2010 \text { and } 4 / 30 / 2013 \\
\text { Patients had no prior quetiapine or lurasidone } \\
\text { First lurasidone or quetiapine claim is the index date }(N=264,039)\end{array}$} \\
\hline \multicolumn{2}{|c|}{$\begin{array}{l}\text { Age } \geq 18 \text { at index date plus 6-month pre- and post-index continuous enrollment with medical and prescription drug } \\
\text { benefits }(\mathrm{N}=119,803)\end{array}$} \\
\hline \multicolumn{2}{|c|}{ Diagnosis of schizophrenia (ICD-9-CM diagnosis code: $295 . x x$ ) in the 6-month pre-index period $(\mathrm{N}=3,120)$} \\
\hline \multicolumn{2}{|c|}{$\begin{array}{l}\text { Switch from oral aripiprazole, asenapine, clozapine, iloperidone, paliperidone, olanzapine, risperidone, or } \\
\text { ziprasidone }(\mathrm{N}=692)\end{array}$} \\
\hline & $\square$ \\
\hline $\begin{array}{l}\text { Lurasidone patients } \\
\qquad(\mathrm{N}=265)\end{array}$ & $\begin{array}{l}\text { Quetiapine patients } \\
(\mathrm{N}=427)\end{array}$ \\
\hline $\begin{array}{l}\text { Lurasidone patients with monotherapy episodes } \\
\qquad(\mathrm{N}=116)\end{array}$ & $\begin{array}{l}\text { Quetiapine patients with monotherapy episodes } \\
\qquad(\mathrm{N}=\mathbf{2 2 0})\end{array}$ \\
\hline
\end{tabular}

Fig. 2 Patients flow through inclusion/exclusion criteria. a. Medicaid patient flow diagram. b. Commercial patient flow diagram. Abbreviations: ICD-9-CM - International Classification of Diseases, Ninth Revision, Clinical Modification

statistical significance in the payer subsamples (Table 2). The average length of hospitalization in the Medicaid population appeared to be shorter compared to the commercial population. The average length of stay for the first hospitalization was significantly shorter for Medicaid patients treated with lurasidone than those treated with quetiapine (Table 2).

\section{Treatment duration}

Approximately $72 \%$ of lurasidone and $68 \%$ of quetiapine treatment episodes were censored due to the end of the study period, $12 \%$ of lurasidone and 15\% of quetiapine discontinued due to a gap of 60 days or more in therapy, and $17 \%$ of both lurasidone and quetiapine treatment episodes ended due to switching to another antipsychotic medication. When compared to the duration of quetiapine treatment episodes, lurasidone treatment duration was modestly but significantly longer (mean \pm SD: $115.4 \pm 49.9$ vs. $123.1 \pm 47.2$ days, $p<0.05)$. Similarly, among those patients who discontinued or switched treatments, duration of lurasidone treatment episodes was longer than quetiapine episodes (mean \pm SD: 81 . $4 \pm 39.7$ vs. $68.3 \pm 33.1$ days, $\mathrm{p}<0.05)$.

\section{Treatment costs}

Among treatment episodes resulting in a hospitalization, the unadjusted mean cost of hospitalization for the Medicaid and commercial populations are reported in Table 2. In the multivariable models that adjusted for pre-index covariates (Fig. 4), the adjusted cost of all- 
Table 1 Pre-index patient characteristics

\begin{tabular}{|c|c|c|c|c|c|c|c|c|c|c|c|c|}
\hline \multirow[t]{3}{*}{ Variable } & \multicolumn{4}{|c|}{ Combined population } & \multicolumn{4}{|c|}{ Medicaid population } & \multicolumn{4}{|c|}{ Commercial population } \\
\hline & \multirow{2}{*}{\multicolumn{2}{|c|}{$\begin{array}{l}\text { Lurasidone } \\
\mathrm{n}=238\end{array}$}} & \multirow{2}{*}{\multicolumn{2}{|c|}{$\begin{array}{l}\text { Quetiapine } \\
\mathrm{n}=435\end{array}$}} & \multirow{2}{*}{\multicolumn{2}{|c|}{$\begin{array}{l}\text { Lurasidone } \\
n=122\end{array}$}} & \multirow{2}{*}{\multicolumn{2}{|c|}{$\begin{array}{l}\text { Quetiapine } \\
n=215\end{array}$}} & \multirow{2}{*}{\multicolumn{2}{|c|}{$\begin{array}{l}\text { Lurasidone } \\
n=116\end{array}$}} & \multirow{2}{*}{\multicolumn{2}{|c|}{$\begin{array}{l}\text { Quetiapine } \\
n=220\end{array}$}} \\
\hline & & & & & & & & & & & & \\
\hline \multicolumn{13}{|l|}{ Demographics } \\
\hline Age, (Mean, SD) & 37.1 & 13.4 & 37.6 & 14.2 & 39.1 & 12.8 & 38.2 & 12.9 & 34.9 & 13.8 & 36.9 & 15.3 \\
\hline Female (N, \%) & 145 & 61 & $225^{*}$ & 52 & 82 & 67 & 129 & 60 & 63 & 54 & 96 & 44 \\
\hline \multicolumn{13}{|l|}{ Comorbidities, (N, \%) } \\
\hline \multicolumn{13}{|l|}{ Psychiatric } \\
\hline Alcohol/Substance Abuse & 53 & 22 & $159^{*}$ & 37 & 41 & 34 & 84 & 39 & 12 & 10 & $75^{*}$ & 34 \\
\hline Anxiety & 67 & 28 & $170^{*}$ & 39 & 39 & 32 & 84 & 39 & 28 & 24 & $86^{*}$ & 39 \\
\hline Bipolar Disorder & 108 & 45 & 231 & 53 & 57 & 47 & 106 & 49 & 51 & 44 & $125^{*}$ & 57 \\
\hline Depression & 99 & 42 & $225^{*}$ & 52 & 51 & 42 & $117^{*}$ & 54 & 48 & 41 & 108 & 49 \\
\hline Personality Disorders & 25 & 11 & 45 & 10 & 18 & 15 & 28 & 13 & 7 & 6 & 17 & 8 \\
\hline \multicolumn{13}{|l|}{ Cardiometabolic } \\
\hline Diabetes & 41 & 17 & 61 & 14 & 25 & 21 & 39 & 18 & 16 & 14 & 22 & 10 \\
\hline Hyperlipidemia & 48 & 20 & 93 & 21 & 30 & 25 & 52 & 24 & 18 & 16 & 41 & 19 \\
\hline Hypertension & 69 & 29 & 144 & 33 & 49 & 40 & 88 & 41 & 20 & 17 & 56 & 25 \\
\hline \multicolumn{13}{|l|}{ Medications, (N, \%) } \\
\hline \multicolumn{13}{|l|}{ Psychiatric } \\
\hline Antidepressants & 177 & 74 & 313 & 72 & 98 & 80 & 169 & 79 & 79 & 68 & 144 & 66 \\
\hline Anxiety & 65 & 27 & $172^{*}$ & 40 & 27 & 22 & $78^{*}$ & 36 & 38 & 33 & 94 & 43 \\
\hline Hypnotics & 80 & 34 & 142 & 33 & 53 & 43 & 84 & 39 & 27 & 23 & 58 & 26 \\
\hline Mood stabilizers & 130 & 55 & 269 & 62 & 67 & 55 & 130 & 61 & 63 & 54 & 139 & 6 \\
\hline Stimulants & 21 & 9 & 22 & 5 & 1 & 1 & 3 & 1 & 20 & 17 & $19^{*}$ & 9 \\
\hline Typical antipsychotics & 23 & 10 & 63 & 15 & 12 & 10 & 29 & 14 & 11 & 10 & 34 & 15 \\
\hline \multicolumn{13}{|l|}{ Other } \\
\hline Antidiabetics & 38 & 16 & 50 & 12 & 22 & 18 & 30 & 14 & 16 & 14 & 20 & 9 \\
\hline Antihypertensives & 62 & 26 & 124 & 29 & 43 & 35. & 72 & 33 & 19 & 16 & 52 & 24 \\
\hline Antilipidemic & 55 & 23 & 76 & 18 & 36 & 29 & $40^{*}$ & 19 & 19 & 16 & 36 & 16 \\
\hline \multicolumn{13}{|c|}{ Switch from atypical antipsychotic } \\
\hline Aripiprazole & 58 & 24 & 90 & 21 & 26 & 21 & 41 & 19 & 32 & 28 & 49 & 22 \\
\hline Asenapine & 24 & 10 & $10^{*}$ & 2 & 12 & 10 & $4^{*}$ & 2 & 12 & 10 & $6^{*}$ & 3 \\
\hline Clozapine & 4 & 2 & 6 & 1 & 2 & 2 & 3 & 1 & 2 & 2 & 3 & 1 \\
\hline lloperidone & 10 & 4 & 13 & 3 & 5 & 4 & 5 & 2 & 5 & 4 & 8 & 4 \\
\hline Paliperidone & 43 & 18 & 74 & 17 & 18 & 15 & 30 & 14 & 25 & 22 & 44 & 20 \\
\hline Olanzapine & 28 & 12 & $18^{*}$ & 4 & 17 & 14 & $11^{*}$ & 5 & 11 & 10 & $7^{*}$ & 3 \\
\hline Risperidone & 56 & 24 & $159^{*}$ & 37 & 27 & 22 & $81^{*}$ & 38 & 29 & 25 & 78 & 35 \\
\hline Ziprasidone & 38 & 16 & 89 & 20 & 23 & 19 & 53 & 25 & 15 & 13 & 36 & 16 \\
\hline \multicolumn{13}{|l|}{ Inpatient admissions, (N, \%) } \\
\hline All-cause & 98 & 41 & $274^{*}$ & 63 & 44 & 36 & $114^{*}$ & 53 & 54 & 47 & $160^{*}$ & 73 \\
\hline Mental health-related & 98 & 41 & $272^{*}$ & 63 & 44 & 36 & $113^{*}$ & 53 & 54 & 47 & $159^{*}$ & 72 \\
\hline Schizophrenia-related & 80 & 34 & $214^{*}$ & $4^{*}$ & 34 & 28 & $95^{*}$ & 44 & 46 & 40 & $119^{*}$ & 54 \\
\hline Total cost, (Mean, SD) ${ }^{a}$ & & & & & 13,883 & 16,721 & 15,008 & 14,086 & 15,379 & 17,352 & $23,061^{*}$ & 30,804 \\
\hline
\end{tabular}

${ }^{a}$ Expenditures for the combined Medicaid/Commercial population are not reported due to different payment structures ${ }^{*} p<0.05$; Statistically significantly different from lurasidone cohort 


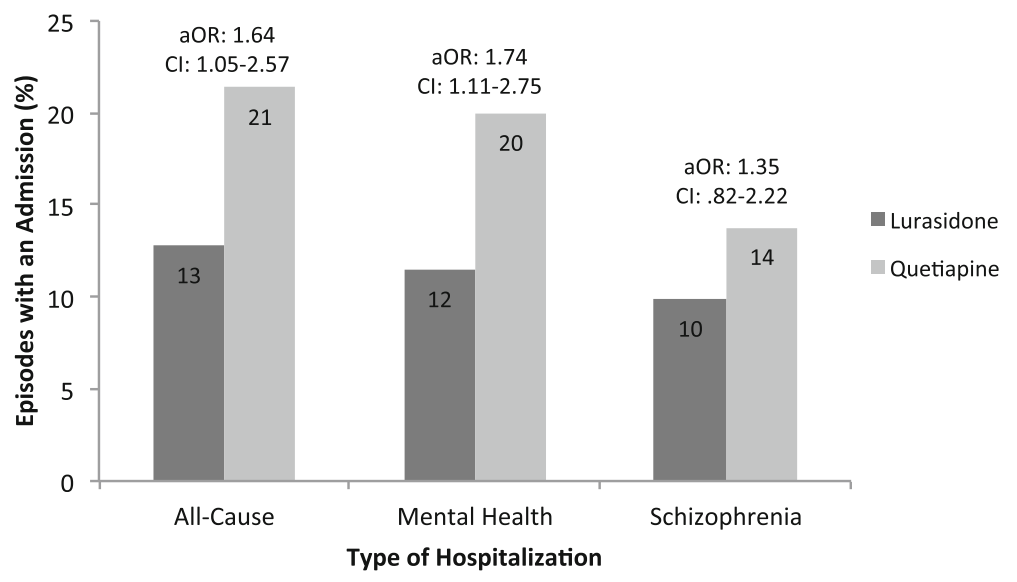

Fig. 3 Percent of episodes with at least one all-cause, mental health, or schizophrenia hospitalization in the combined study cohorts. Abbreviations: aOR - Adjusted Odds Ratio, $\mathrm{Cl}$ - 95\% Confidence Interval. Multivariable generalized linear models with binomial distribution and logit link were utilized. The models accounted for within-patient correlation among patients with multiple episodes, and controlled for the variables age, gender, health plan (Medicaid vs. commercial), pre-index hospitalizations, use of anti-anxiety medication, preexisting anxiety, depression, and alcohol/substance abuse

cause admissions for those with an admission in the Medicaid population was $\$ 15,424$ for lurasidone and $\$ 22,036$ for quetiapine $(p=0.17)$. In the commercial population, the adjusted cost of all-cause admissions for treatment episodes with an admission was $\$ 20,049$ for lurasidone and $\$ 23,490$ for quetiapine $(p=0.61)$.

Average total costs, which included hospital admissions, emergency room visits, outpatient services, and prescription costs were computed among all treatment episodes. The average total costs in the postperiod were not statistically significantly different between lurasidone and quetiapine (Medicaid: $\$ 11,694$ vs $\$ 12,041, p=0.84$; commercial: $\$ 7488$ vs. $\$ 11,158, p$ $=0.14$ ). In the Medicaid cohort, hospital costs made up $20.1 \%$ of the total costs for lurasidone treatment and $42.1 \%$ for quetiapine treatment, whereas prescription costs made up $32.6 \%$ of the total costs for lurasidone treatment and $21.5 \%$ for quetiapine treatment. Similarly, hospital costs in the commercial cohort made up $22.1 \%$ of the total costs for lurasidone treatment and $48.4 \%$ for quetiapine treatment, whereas prescription costs made up $45.9 \%$ of the total costs for lurasidone

Table 2 Hospitalizations during the 6-month follow up period

\begin{tabular}{|c|c|c|c|c|c|c|c|c|}
\hline \multirow{4}{*}{$\begin{array}{l}\text { Variable } \\
\text { Episodes }(\mathrm{N})^{\mathrm{a}}\end{array}$} & \multicolumn{4}{|c|}{ Medicaid population } & \multicolumn{4}{|c|}{ Commercial population } \\
\hline & \multicolumn{2}{|c|}{ Lurasidone } & \multicolumn{2}{|c|}{ Quetiapine } & \multicolumn{2}{|c|}{ Lurasidone } & \multicolumn{2}{|c|}{ Quetiapine } \\
\hline & \multicolumn{2}{|l|}{$n=122$} & \multicolumn{2}{|l|}{$\mathrm{n}=215$} & \multicolumn{2}{|l|}{$n=116$} & \multicolumn{2}{|l|}{$n=220$} \\
\hline & 125 & - & 226 & - & 118 & - & 223 & - \\
\hline \multicolumn{9}{|l|}{ All-cause hospitalizations } \\
\hline Episodes with $\geq 1$ admission, (N, \%) & 19 & 15 & 52 & 23 & 12 & 10 & $44^{*}$ & 20 \\
\hline Length of stay (first admission), (Mean, SD) & 5.4 & 4.3 & $6.7^{*}$ & 4.8 & 10.9 & 14.5 & 9.3 & 8.8 \\
\hline Cost, among episodes with an admission (Mean, SD) & 15,448 & 13,741 & $22,012^{*}$ & 23,581 & 16,265 & 16,377 & $27,368^{*}$ & 46,415 \\
\hline \multicolumn{9}{|l|}{ Mental health-related hospitalizations } \\
\hline Episodes with $\geq 1$ admission, (N, \%) & 18 & 14 & 48 & 21 & 10 & 9 & $42^{*}$ & 19 \\
\hline Length of stay (first admission), (Mean, SD) & 5.6 & 4.4 & $6.8^{*}$ & 5.0 & 12.5 & 15.5 & $9.8^{*}$ & 8.8 \\
\hline Cost, among episodes with an admission (Mean, SD) & 15,388 & 13,609 & $22,272^{*}$ & 24,385 & 16,512 & 17,903 & $27,398^{*}$ & 46,476 \\
\hline \multicolumn{9}{|l|}{ Schizophrenia-related hospitalizations } \\
\hline Episodes with $\geq 1$ admission, (N, \%) & 16 & 13 & 36 & 16 & 8 & 7 & 26 & 12 \\
\hline Length of stay (first admission), (Mean, SD) & 5.6 & 4.7 & $7.6^{*}$ & 5.0 & 14.4 & 17.0 & 13.8 & 21.7 \\
\hline Cost, among episodes with an admission (Mean, SD) & 14,193 & 12,876 & $21,579^{*}$ & 24,034 & 17,863 & 19,745 & 18,514 & 17,249 \\
\hline
\end{tabular}

${ }^{a}$ Monotherapy treatment episodes were defined as patients having more than one lurasidone or quetiapine prescription without overlapping other antipsychotics during the post-index period. As some patients had multiple episodes, the $\mathrm{N}$ value in this row refers to the number of episodes in the sample that were evaluated * $(p<.05)$; Statistically significantly different from lurasidone cohort 


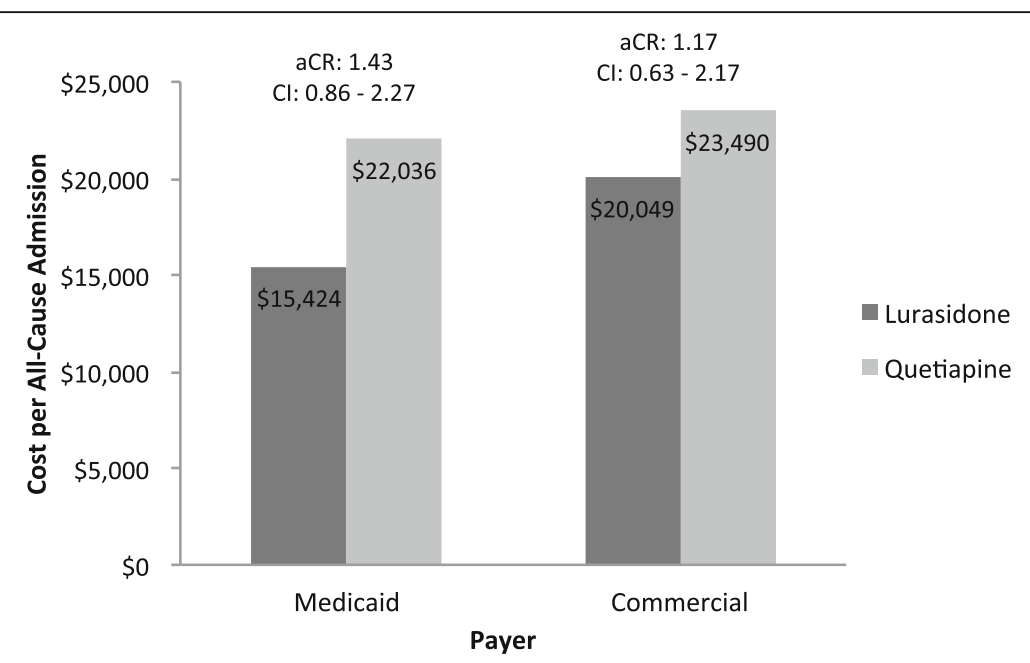

Fig. 4 Adjusted all-cause admission costs among hospitalized patients by insurance type. Abbreviations: aCR - Adjusted Cost Ratio, Cl - 95\% Confidence Interval. Multivariable generalized linear models with a gamma distribution and log link were utilized. The models accounted for the within-patient correlation among patients with multiple episodes, and controlled for age, gender, pre-index hospitalizations, use of anti-anxiety medication, preexisting anxiety, depression, and alcohol/substance abuse, and pre-index total cost. Adjusted costs are based on SAS LS Means

treatment and $18.6 \%$ for quetiapine treatment. Additional details of the multivariate results are given in the supplemental online material (Additional file 2).

\section{Discussion}

This real-world analysis of patients with schizophrenia in the U.S., which adjusted for a range of pre-index clinical characteristics and pre-index hospitalizations, found that following a switch from other atypical antipsychotics, treatment with lurasidone was associated with significantly lower rates of all-cause and mental health-related hospital admissions, and similar rates of schizophrenia-related admissions compared with patients switching to quetiapine. In addition, patients switching to lurasidone had significantly longer treatment duration than those switching to quetiapine, potentially due to differences in efficacy or tolerability [30, 31]. The results of this study confirm and extend those of a previously reported prospective trial that demonstrated reduced risk of hospitalization in patients with schizophrenia treated with lurasidone versus quetiapine XR [24]. In the extension study, after 12 months, patients with schizophrenia initially randomized to lurasidone $(n=139)$ had a significantly lower rate of hospitalization than those initially randomized to quetiapine XR $(n=79 ; 9.8 \%$ vs $23.1 \%$, $p=0.049)$ [24].

In addition, we found that hospitalization costs associated with lurasidone treatment were lower than with those associated with quetiapine treatment in both commercial and Medicaid populations in this study. Hospitalization costs are the largest contributor to the overall healthcare costs for patients with schizophrenia [32, 33]. They are not only expensive from the perspective of direct costs, but may be an indicator of worse clinical outcomes [34]. These findings suggest that lurasidone may be associated with lower healthcare costs compared with quetiapine and may potentially offer better health outcomes among patients with schizophrenia.

While average daily doses for lurasidone and quetiapine in the current real-world study $(74 \mathrm{mg}$ and $306 \mathrm{mg}$, respectively) were lower than those reported in the extension study [24], these doses were consistent with long-term clinical studies in real-world settings. For example, an average daily quetiapine dose of $377 \mathrm{mg} /$ day was reported in a 3-year prospective study of outpatients with schizophrenia [35], and an average daily lurasidone dose of $87.8 \mathrm{mg} /$ day was reported in a 22-month open-label extension study of patients with schizophrenia [36]. The current study therefore further supports the previous findings that lurasidone may be associated with reduced risk for hospitalization in patients with schizophrenia compared to other atypical antipsychotic agents.

At the time of the study (2010-2013), quetiapine had been available since 1997, while lurasidone had just become available in 2010 [22]. Treatmentresistant patients may be more likely to be prescribed a new medication; therefore, patients who switched to lurasidone may have been more severely ill during the study timeframe. However, only four patients treated with lurasidone and two treated with quetiapine were switched from clozapine, a medication generally 
reserved for treatment-resistant patients [2]. Nonetheless, there may have been a potential for more severely ill patients to receive lurasidone.

Although atypical antipsychotics significantly reduce the symptoms of schizophrenia, poor treatment duration remains a common clinical problem [18, 37]. Maintaining treatment is essential to achieve optimal clinical benefit, and can reduce the risk of hospitalizations [10, 38]. In this study, treatment duration was modestly, but statistically significantly, longer in the lurasidone cohort than in the quetiapine cohort (123. 1 days versus 115.4 days). Treatment options that improve treatment duration are important for the effective management of schizophrenia. The results from this claims analysis, taken together with the results from the long-term prospective double-blind lurasidone versus quetiapine XR clinical trial, suggest that lurasidone may be a more effective treatment than quetiapine for patients with schizophrenia switching from other atypical antipsychotics.

While length of hospital stay appeared to be numerically longer in the commercial population than in the Medicaid population for both lurasidone (14.4 days for commercial vs. 5.6 days for Medicaid) and quetiapine cohorts (13.8 days for commercial vs. 7.6 days for Medicaid) in this analysis, prior national estimates for U.S. schizophrenia-related hospitalizations have showed longer length of stay in Medicaid patients compared to commercial patients (10.9 days for Medicaid vs. 9.1 days for commercial insurance) [39]. The reasons for the differences in the early study and the current study are unclear, but could be due to changes in the composition of beneficiaries or changes in fixed payment rates between payer types that appear to affect length of stay [40].

This study has several limitations inherent to research using administrative claims data. Administrative claims data is collected for reimbursement rather than research purposes. While we have adjusted for many known confounders, other clinical measures that are not available in administrative claims data, may potentially act as additional confounders. Thus the study results, while interesting, may need to be interpreted with caution. For example, the analysis was not able to control for race/ ethnicity. In addition, not all patient comorbidities were adjusted for in the analyses. In order to maximize the sample size, patients were included if a single claim with a diagnosis of schizophrenia was present. As with all administrative claims database analyses, medication duration was based on prescription fill dates rather than directly monitored medication administration. Lurasidone and quetiapine are both approved for the treatment of schizophrenia and bipolar depression, but further research would be necessary to determine whether these findings apply to patients with bipolar disorder. Findings from this study pertain to a subset of patients with schizophrenia who switched specific antipsychotics covered under Medicaid or Commercial health plans, thereby limiting the ability to fully extrapolate the findings to all patients. There was no statistical significant difference in schizophrenia-related hospitalization rates, potentially due to the fewer number of events requiring a larger sample size to detect a difference. The direction of the effect for schizophrenia-related hospitalizations matched that for all-cause and mental health-related hospitalizations and the lack of a statistically significance difference does not necessarily imply the lack of a clinical difference. We believe that the commercial data used in this study is representative of the US noninstitutionalized commercially-insured population and that the Medicaid data, which included 12 state Medicaid programs, is representative of all 50 states. The 6-month analytical timeframe was chosen a priori to be sufficiently long to capture hospitalizations related to the study medications. Results of this study are informative about six-months following an antipsychotic switch.

\section{Conclusions}

The results of this real-world analysis suggest that patients with schizophrenia who switched to lurasidone monotherapy had fewer all-cause and mental health-related hospitalizations, but not schizophrenia-related hospitalizations, compared to patients who received quetiapine. Lurasidone treatment was associated with modestly longer duration compared to quetiapine in this study. Given the inverse relationship between treatment duration and hospitalization, it is possible that the higher persistency rates with lurasidone may have contributed to fewer relapses that require hospitalization. These results may inform clinical decision-making as well as value-based decision-making associated with the treatment of schizophrenia.

\section{Additional files}

Additional file 1: ICD-9-CM Diagnosis Codes. (DOCX 52 kb)

Additional file 2: Multivariate Model Results. Table S1. Multivariate results for all-cause hospital admission in combined Medicaid and commercial insurance. Table S2. Multivariate results for mental-health hospital admission in combined Medicaid and commercial insurance. Table S3. Multivariate results for schizophrenia-related hospital admission in combined Medicaid and commercial insurance. Table S4. Multivariate results for all-cause hospital costs in commercial insurance among treatment episodes with an 
admission. Table S5. Multivariate results for all-cause hospital costs in Medicaid among treatment episodes with an admission. (DOCX 76 kb)

\section{Abbreviations}

ANOVA: Analysis of variance; FDA: U.S. Food and Drug Administration; HIPAA: Health Insurance Portability and Accessibility Act; ICD-9 CM: International Classification of Disease, Ninth Edition, Clinical Modification; SAS: Statistical Analysis System; SD: Standard deviation; XR: Extended release

\section{Acknowledgements}

Assistance in study design, data analysis, results interpretation, and report writing was provided by Debra Irwin and Nicole Meyer, who were paid by Sunovion Pharmaceuticals Inc. and are employees of Truven Health Analytics. Editorial and writing assistance for this manuscript was provided by Michael Stensland, who was compensated by Sunovion Pharmaceuticals Inc.

\section{Funding}

The study was funded by Sunovion Pharmaceuticals Inc., Marlborough, MA, USA. Three authors (AL, DN-M, and KR) are full time employees of Sunovion Pharmaceuticals Inc. and were involved with the study conception and design, protocol and statistical analysis plan development, interpretation of the results, drafting of the manuscript, and critical revision of the manuscript. Truven Health Analytics LLC completed the data analysis under the guidance of Sunovion Pharmaceuticals Inc.

\section{Availability of data and materials}

The data that support the findings of this study are available from the Truven Health MarketScan ${ }^{\circledast}$ Medicaid Multi-State Database and Truven Health MarketScan ${ }^{\oplus}$ Commercial Claims and Encounters Database, and was fully compliant with the Health Insurance Portability and Accountability Act (HIPAA) of 1996. The methodology used in this study was not proprietary. Restrictions apply to the availability of these data, which were used under license for the current study, and so are not publicly available. Data are however available from the authors upon reasonable request and with permission.

\section{Authors' contributions}

All authors were involved in the study conception and design (JWN, AL, $\mathrm{DN}-\mathrm{M}$, and KR), interpretation of the data (JWN, AL, DN-M, and KR), drafting of the manuscript (JWN, AL, DN-M, and KR), and the critical revisions of the manuscript (JWN, AL, DN-M, and KR). All authors (JWN, AL, DN-M, and KR) read and approved the final version of the manuscript for submission.

\section{Ethics approval and consent to participate}

All study data were de-identified according to the Health Insurance Portability and Accountability Act (HIPAA) of 1996, and therefore the study did not require approval or waiver from an institutional review board. Data access was provided based on a licensing agreement between Truven Health Analytics LLC and Sunovion Pharmaceuticals Inc and data analysis was provided by Truven Health Analytics LLC.

\section{Consent for publication}

Not applicable.

\section{Competing interests}

Author JN is an unpaid consultant of Sunovion Pharmaceuticals Inc. NG, KR and $\mathrm{AL}$ are employees of Sunovion Pharmaceuticals Inc. The authors attest that all financial or other relationships that could be construed as a conflict of interest, and that all sources of financial support for this study, have been disclosed as indicated.

\section{Publisher's Note}

Springer Nature remains neutral with regard to jurisdictional claims in published maps and institutional affiliations.

\section{Author details}

${ }^{1}$ Charles E. Schmidt College of Medicine, Florida Atlantic University, Boca Raton, FL, USA. ${ }^{2}$ GHEOR, Sunovion Pharmaceuticals Inc., Marlborough, MA, USA. ${ }^{3}$ Research \& Development, Sunovion Pharmaceuticals Inc., Fort Lee, NJ, USA.
Received: 28 April 2017 Accepted: 16 March 2018

Published online: 04 April 2018

\section{References}

1. van Os J, Kapur S. Schizophrenia. Lancet. 2009:374:635-45.

2. Lehman AF, Lieberman JA, Dixon LB, McGlashan TH, Miller AL, Perkins DO, et al. Practice guideline for the treatment of patients with schizophrenia, second edition. Am J Psychiatry. 2004;161:1-56.

3. National Alliance on Mental IIness. Schizophrenia Fact Sheet. 2015. https:// www.nami.org/NAMI/media/NAMI-Media/Images/FactSheets/SchizophreniaFS.pdf. Accessed 26 Apr 2017.

4. American Psychiatric Association. Diagnostic and Statistical Manual of Mental Disorders, 5th Edition: DSM-5. 5 edition. Washington, D.C: American Psychiatric Publishing; 2013.

5. Cloutier M, Aigbogun MS, Guerin A, Nitulescu R, Ramanakumar AV, Kamat SA, et al. The economic burden of schizophrenia in the United States in 2013. J Clin Psychiatry. 2016;77:764-71.

6. dosReis S, Johnson E, Steinwachs D, Rohde C, Skinner EA, Fahey M, et al. Antipsychotic treatment patterns and hospitalizations among adults with schizophrenia. Schizophr Res. 2008;101:304-11.

7. Fitch K, Iwasaki K, Villa KF. Resource utilization and cost in a commercially insured population with schizophrenia. Am Health Drug Benefits. 2014;7:18-26.

8. Abouzaid S, Tian H, Zhou H, Kahler KH, Harris M, Kim E. Economic burden associated with extrapyramidal symptoms in a medicaid population with schizophrenia. Community Ment Health J. 2014:50:51-8.

9. Markowitz M, Karve S, Panish J, Candrilli SD, Alphs L. Antipsychotic adherence patterns and health care utilization and costs among patients discharged after a schizophrenia-related hospitalization. BMC Psychiatry. 2013;13:246.

10. Weiden PJ, Kozma C, Grogg A, Locklear J. Partial compliance and risk of rehospitalization among California Medicaid patients with schizophrenia. Psychiatr Serv. 2004;55:886-91.

11. Hasan A, Falkai P, Wobrock T, Lieberman J, Glenthoj B, Gattaz W, et al. World Federation of Societies of biological psychiatry (WFSBP) guidelines for biological treatment of schizophrenia, part 1: update 2012 on the acute treatment of schizophrenia and the management of treatment resistance. World J Biol Psychiatry. 2012;13:318-78.

12. Leucht S, Cipriani A, Spineli L, Mavridis D, Örey D, Richter F, et al. Comparative efficacy and tolerability of 15 antipsychotic drugs in schizophrenia: a multiple-treatments meta-analysis. Lancet. 2013;382:951-62.

13. Davis JM, Chen N, Glick ID. A meta-analysis of the efficacy of secondgeneration antipsychotics. Arch Gen Psychiatry. 2003 Jun;60(6):553-64.

14. Khasawneh FT, Shankar GS. Minimizing cardiovascular adverse effects of atypical antipsychotic drugs in patients with schizophrenia. In Cardiol Res Pract 2014. http://www.ncbi.n/m.nih.gov/pmc/articles/PMC3932258/. Accessed 28 Mar 2016.

15. American Diabetes Association. American Psychiatric Association, American Association of Clinical Endocrinologists, north American Association for the Study of obesity. Consensus development conference on antipsychotic drugs and obesity and diabetes. J Clin Psychiatry. 2004;65:267-72.

16. Graham KA, Cho H, Brownley KA, Harp JB. Early treatment-related changed in diabetes and cardiovascular disease risk markers in first episode psychosis subjects. Schizophr Res. 2008;101:287-94.

17. Meyer JM, Davis VG, Goff DC, McEvoy JP, Nasrallah HA, Davis SM, et al. Change in metabolic syndrome parameters with antipsychotic treatment in the CATIE schizophrenia trial: prospective data from phase 1. Schizophr Res. 2008;101:273-86.

18. Lieberman JA, Stroup TS, McEvoy JP, Swartz MS, Rosenheck RR, Perkins D, et al. Effectiveness of antipsychotic drugs in patients with chronic schizophrenia. N Engl J Med. 2005;353:1209-23.

19. Stroup TS, Lieberman JA, McEvoy J, Swartz M, Davis SM, Rosenheck RR, et al Effectiveness of olanzapine, quetiapine, risperidone, and Zziprasidone in patients with chronic schizophrenia following discontinuation of a previous atypical antipsychotic. Am J Psychiatry. 2006;163:611-22.

20. McEvoy JP, Lieberman JA, Stroup TS, Davis SM, Meltzer H, Rosenheck RR, et al. Effectiveness of clozapine versus olanzapine, quetiapine, and risperidone in patients with chronic schizophrenia who did not respond to prior atypical antipsychotic treatment. Am J Psychiatry. 2006;163:600-10 
21. Stroup TS, Lieberman JA, McEvoy JP, Davis SM, Swartz MS, Keefe R, et al. Results of phase 3 of the CATIE schizophrenia trial. Schizophr Res. 2009;107:1-12.

22. Latuda Prescribing Information. 2017. http://www.latuda.com/ LatudaPrescribingInformation.pdf. Accessed 14 Apr 2017.

23. Seroquel Prescribing Information. 2016. http://www.azpicentral.com/ seroquel/seroquel.pdf.

24. Loebel A, Cucchiaro J, Xu J, Sarma K, Pikalov A, Kane JM. Effectiveness of lurasidone vs. quetiapine XR for relapse prevention in schizophrenia: a 12month, double-blind, noninferiority study. Schizophr Res. 2013;147:95-102.

25. US Department of Health \& Human services. Who is eligible for Medicaid? 2015. http://www.hhs.gov/answers/medicare-and-medicaid/who-is-eligiblefor-medicaid/index.html. Accessed 09 Nov 2016.

26. United States Congress. Patient Protection and Affordable Care Act [Internet]. Sect. 3025, 111-148 Mar 23, 2010. Available from: http://www. gpo.gov/fdsys/pkg/PLAW-111publ148/pdf/PLAW-111publ148.pdf

27. US Bureau of Labor Statistics. Measuring price change for medical care in the CPI. 2010. http://www.bls.gov/cpi/cpifact4.htm\#1a. Accessed 27 Mar 2017.

28. Gianfrancesco F, Wang RH, Pesa J, Rajagopalan K. Hospitalisation risks in the treatment of schizophrenia in a Medicaid population: comparison of antipsychotic medications. Int J Clin Pract. 2006;60:1419-24.

29. Mihaylova B, Briggs A, O'Hagan A, Thompson SG. Review of statistical methods for analysing healthcare resources and costs. Health Econ. 2011;20:897-916.

30. Ascher-Svanum $H$, Nyhuis AW, Stauffer $V$, Kinon BJ, Faries DE, Phillips GA et al. Reasons for discontinuation and continuation of antipsychotics in the treatment of schizophrenia from patient and clinician perspectives. Curr Med Res Opin. 2010;26:2403-10.

31. Stroup TS, Lieberman JA, McEvoy JP, Swartz MS, Davis SM, Capuano GA, et al. Effectiveness of olanzapine, quetiapine, and risperidone in patients with chronic schizophrenia after discontinuing perphenazine: a CATIE study. Am J Psychiatry. 2007;164:415.

32. Marcus SC, Olfson M. Outpatient antipsychotic treatment and inpatient costs of schizophrenia. Schizophr Bull. 2008:34:173-80.

33. Ascher-Svanum H, Nyhuis AW, Faries DE, Kinon BJ, Baker RW, Shekhar A. Clinical, functional, and economic ramifications of early nonresponse to antipsychotics in the naturalistic treatment of schizophrenia. Schizophr Bull. 2008:34:1163-71.

34. Tunis SL, Ascher-Svanum H, Stensland M, Kinon BJ. Assessing the value of antipsychotics for treating schizophrenia: the importance of evaluating and interpreting the clinical significance of individual service costs. PharmacoEconomics. 2004;22:1-8.

35. Haro JM, Suarez D, Novick D, Brown J, Usall J, Naber D. Three-year antipsychotic effectiveness in the outpatient care of schizophrenia: observational versus randomized studies results. Eur Neuropsychopharmacol. 2007;17:235-44.

36. Correll C, Cucchiaro J, Silva R, Hsu J, Pikalov A, Loebel A. Long-term safety and effectiveness of lurasidone in schizophrenia: a 22-month, open-label extension study. CNS Spectrums. 2016:21:383-402.

37. Valenstein M, Blow FC, Copeland LA, McCarthy JF, Zeber JE, Gillon L, et al. Poor antipsychotic adherence among patients with schizophrenia: medication and patient factors. Schizophr Bull. 2004;30:255.

38. Ren XS, Qian S, Kazis LE. An alternative approach to measuring treatment persistence with antipsychotic agents among patients with schizophrenia in the veterans health administration. Neuropsychiatr Dis Treat. 2007:3:277-84.

39. Stensland M, Watson PR, Grazier KL. An examination of costs, charges, and payments for inpatient psychiatric treatment in community hospitals. Psychiatr Serv Wash DC. 2012;63:666-71.

40. Tulloch AD, Fearon P, David AS. Length of stay of general psychiatric inpatients in the United States: systematic review. Adm Policy Ment Health Ment Health Serv Res. 2011;38:155-68.

\section{Submit your next manuscript to BioMed Central and we will help you at every step:}

- We accept pre-submission inquiries

- Our selector tool helps you to find the most relevant journal

- We provide round the clock customer support

- Convenient online submission

- Thorough peer review

- Inclusion in PubMed and all major indexing services

- Maximum visibility for your research

Submit your manuscript at www.biomedcentral.com/submit
Biomed Central 